\title{
Kajian Tarif Angkutan Umum Bus Damri Rute BIL - Kota Matram Berdasarkan Biaya Operasional Kendaraan
}

\author{
*Titik Wahyuningsih, Hariyadi, Anwar Efendy, Ana Dinika \\ ${ }^{1}$ Teknik Sipil, Universitas Muhammadiyah Mataram \\ * titiwahyu24@yahoo.co.id
}

INFO ARTIKEL
Riwayat Artikel:
Diterima: 28 -07-2020
Disetujui: $29-08-2020$

\section{Kata Kunci:}

Angkutan Umum

Bus Damri

BOK

Tarif

\begin{abstract}
ABSTRAK
Abstrak: Meningkatnya jumlah perjalanan orang di Kota Mataram memicu terjadinya permintaan angkutan transportasi umum yang memadai baik dari segi kuantitas maupun kualitasnya. Bus Damri adalah salah satu transportasi yang menyediakan jasa angkutan umum penumpang dengan salah-satu rutenya yaitu Bandara Internasional Lombok (BIL) Mataram. Adapun tujuan dari penelitian ini yaitu untuk mengetahui seberapa besar tarif angkutan penumpang Bus Damri berdasarkan biaya oprasional kendaraan (BOK) rute BIL Mataram. Metode yang digunakan untuk menganalisa besar tarif angkutan penumpang berdasarkan BOK yaitu menggunakan metode $\mathrm{PCl}$ (Pacific Consultan Internasional). Berdasrkan hasil analisa diketahui BOK Bus Damri yaitu sebesar Rp 2.788.439, sedangkan hasil analisa data perhitungan tarif berdasarkan BOK didapatkan tarif rata - rata pada waktu Pagi Rp15.015, Siang Rp 13.223 dan Sore Rp 42.262, dengan tarif rata-rata sebesar Rp 23.499,89. Adapun besar tarif sebenarnya Bus Damri rute BIL - Mataram adalah Rp 30.000, dari hasil tersebut menunjukan bahwa hasil analisa tarif dengan tarif sebenarnya masih sesuai.
\end{abstract}

\begin{abstract}
The increasing amount of people traveling in the city of Mataram causes the demand for satisfactory public transportation both in terms of quantity and quality. Damri Bus is one of the transportation that provides passenger public transportation services with one of the routes, specifically Lombok International Airport (LIA) - Mataram. The purpose of this research is to find out how much the Damri Bus passenger transportation rates are based on vehicle operating costs (VOC) route BIL - Mataram. The method used to analyze passenger transportation rates based on VOC is using the PCI (Pacific International Consultant) method. Based on the results of the analysis, it is known that the Damri Bus VOC is $R p 2,788,439$, while the results of the data analysis based on the VOC obtained average rates in the Morning is Rp15,015, in the Noon is Rp 13,223 and in the Afternoon is Rp 42,262, with an average tariff is $R p 23,499,89$. The actual tariff of Damri Bus routes BIL - Mataram is $R p .30,000$, the results show that the results of the tariff analysis with the actual tariff are still appropriate.
\end{abstract}

\section{A. LATAR BELAKANG}

Meningkatnya jumlah penduduk di Kota Mataram setiap tahunnya menyebabkan kebutuhan transportasi juga bertambah, hal ini menyebabkan pengunanaan angkutan umum pertahunnya berkurang dan angkutan pribadi bertambah. Badan Pusat Statistik Kota Mataram, (2020) [1] yang tercantum pada Gambar 1 dan Tabel 1.

Angkutan umum merupakan sarana penting yang dibutuhkan oleh masyarakat perkotaan dalam rangka memenuhi kebutuhan masyarakat dalam beraktifitas. Sebagai sarana transportasi umum harus dapat memberikan pelayanan yang baik terhadap para penggunanya, baik dari kenyamanan, ketepatan waktu dan biaya yang terjangkau bagi seluruh lapisan masyarakat [2]. Salah satu angkutan umum di Kota Mataram adalah Bus Damri yang melayani berbagai rute di Pulau Lombok, salah satunya yakni rute Kota
Mataram menuju ke Bandara Internasional Lombok (BIL) dengan tarif yang telah ditetapkan sebesar Rp. 30.000 .

Proyeksi Jumlah Penduduk Kota Mataram Tahun 2011 2020

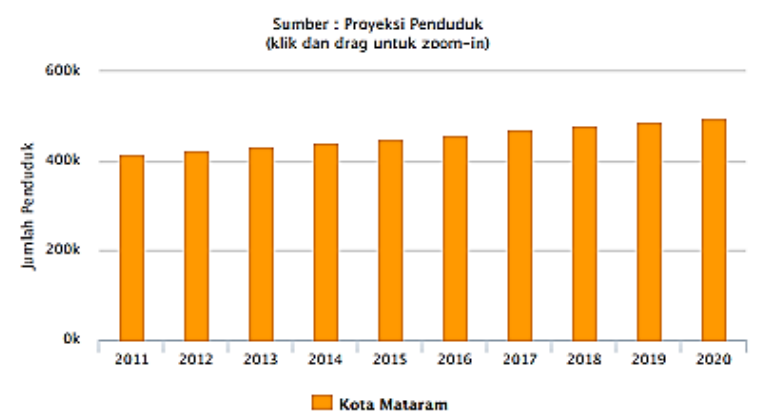

Gambar 1. Penduduk Kota Mataram dalam Angka 2020 Sumber: BPS Kota Mataram, 2020.

Penentuan tarif dan kebijakan dari suatu angkutan umum merupakan elemen paling penting dalam operasi 
bus dan mempengaruhi sikap penumpang dalam melakaukan perjalanan. Banyak variabel yang dapat mempengaruhi penentuan tarif, contohnya yaitu kondisi ekonomi masyarakat, biaya pemeliharaan suku cadang, harga bahan bakar, sarana dan prasarana dan sebagainya yang dikategorikan sebagai Biaya Operasional Kendaraan atau (BOK) [3].

Tabel 1. Persentase Data Penggunaan Moda Transportasi di Kota Mataram, 2011-2015

\begin{tabular}{|l|r|r|r|r|r|r|}
\hline Moda Transportasi & \multicolumn{7}{c}{ Persentase Penggunaan Moda Transportasi (Persen) } \\
\hline Angkutan Kota & 12.05 & 7.12 & 7.12 & 5 & 5 \\
\hline Mobil Pribadi & 16.65 & 16.65 & 17.50 & 17.50 & 17.55 \\
\hline Sepeda Motor/Ojek & 61.57 & 68.57 & 67.86 & 70.05 & 70.10 \\
\hline Sepeda & 6.37 & 4.37 & 4.30 & 4.30 & 4.40 \\
\hline Cidomo & 1.06 & 1.99 & 1.97 & 1.95 & 1.85 \\
\hline Jalan Kaki & 2.30 & 1.30 & 1.25 & 1.20 & 1.10 \\
\hline Lainnya & 0 & 0 & 0 & 0 & 0 \\
\hline Jumlah & 100 & 100 & 100 & 100 & 100 \\
\hline
\end{tabular}

Biaya Operasional Kendaraan (BOK) adalah biaya total yang dibutuhkan untuk mengoperasikan sebuah kendaraan [4]. Tarif dasar untuk Bus Damri dirasa masyarakat pengguna Bus Damri masih terlalu mahal, maka diperlukan analisis tentang tarif angkutan Bus Damri rute Bandara Internasional Lombok (BIL) ke Kota Mataram untuk mengetahui besaran tarif berdasarkan Biaya Operasional Kendaraan (BOK).

\section{B. METODE PENELITIAN}

Kegiatan penelitian akan dilaksanakan di jalur

Bandara Internasional Lombok (BIL) ke Kota Mataram Y = 0,00057 x S2 - 0,06130 x S + 3,317530 x Rp 29.700 (Pool Damri Mataram, Sweta) sepanjang $\pm 29 \mathrm{~km}$, yang (2) berada di Desa Tanak Awu Kecamatan Pujut Kabupaten Lombok Tengah. Rute penelitian yaitu yang bergaris hijau dan termasuk kedalam kategori jalan arteri primer, untuk lebih jeasnya dapat dilihat pada Gambar 2 dan Gambar 3.

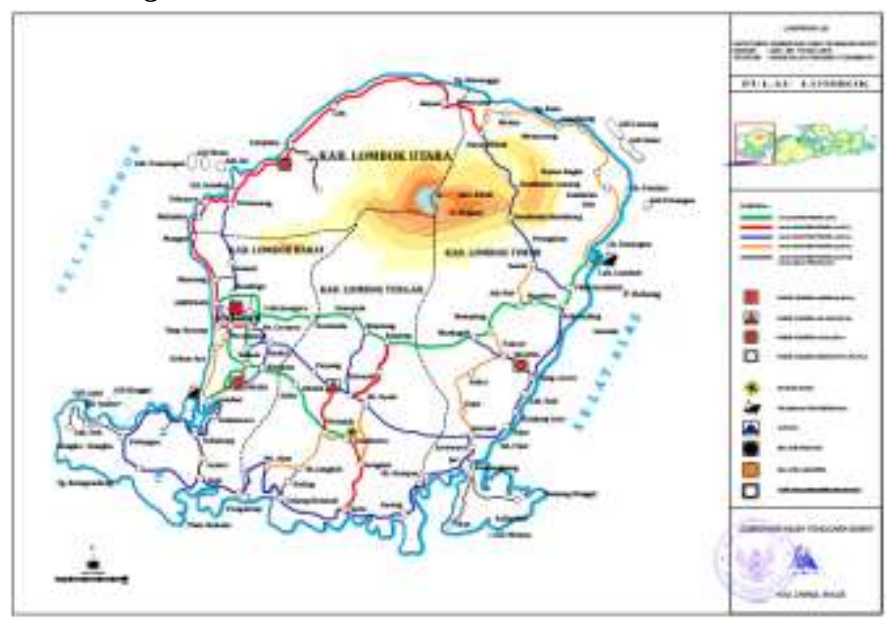

Gambar 1. Peta Rute Perjalanan Bus Damri.

Biaya Operasional Kendaraan (BOK) adalah biaya total yang dibutuhkan suatu kendaran untuk beroperasi pada kondisi lalu lintas dan jalan untuk satu jenis kendaraan per kilometer jarak tempuh ( $\mathrm{Rp} / \mathrm{km})$. Biaya Operasional Kendaraan (BOK) ini dihitung dengan menggunakan metode Pacific Consultant International (PCI) [5].

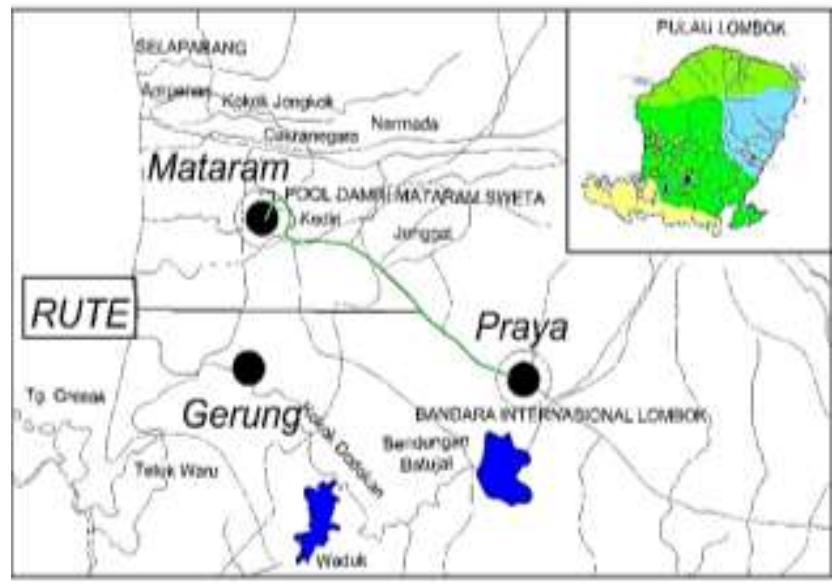

Gambar 3. Peta Rute Pool Damri Mataram - BIL

Adapun persamaan model PCI yang digunakan dalam perhitungan $\mathrm{BOK}$ tersebut adalah sebagai berikut (Bus Damri termasuk Bus Kecil/Sedang) :

1. Konsumsi Bahan Bakar

$\mathrm{Y}=\mathrm{o}, 06846 \times \mathrm{S} 2-8,02987 \times \mathrm{S}+340,604 \times \mathrm{Rp} 5.150$ (1)

Dimana:

$\mathrm{Y}=$ Konsumsi bahan bakar (liter $/ 1000 \mathrm{~km}$ )

$\mathrm{S}=$ Running speed (Km/Jam)

2. Konsumsi Oli Mesin

3. Biaya Pemakaian Ban

$\mathrm{Y}=0,0012356 \times \mathrm{S}-\mathrm{0,0064667}$

$\mathrm{Y}^{\prime}=\mathrm{Y}$ x Jumlah Ban x Harga Ban/1000 Km

4. Biaya Pemeliharaan

Biaya Pemeliharaan untuk Onderdil

$\mathrm{Y}=0,0000320 \times \mathrm{S}+0,0020891$

$\mathrm{Y}_{1}^{\prime}=\mathrm{Y}$ x Nilai Kendaraan/1000 Km

- Biaya Pemeliharaan untuk Pekerja

$\mathrm{Y}=0,02311 \times \mathrm{S}+1,97733$

Y2' = Y x Ongkos Mekanik Perhari/10oo Km (8)

- Biaya Pemeliharaan Total

$\mathrm{Y}=\mathrm{Y} 1^{\prime}+\mathrm{Y} 2^{\prime}$

5. Biaya Penyusutan Kendaraan

$\mathrm{Y}=1 /((8,756 \times \mathrm{S})+350) \times$ harga kendaraan

6. Biaya untuk Suku Bunga

$\mathrm{Y}=120 /(2500 \mathrm{~S}) \times \mathrm{0,5} \times \mathrm{x}$ harga kendaraan

7. Biaya untuk Asuransi

$\mathrm{Y}=(40,0 \times 0,5) /(2500 \mathrm{~S}) \times$ harga kendaraan 
8. Biaya Crew

$\mathrm{Y}=1000 / \mathrm{S} \times$ upah crew perhari (faktor pengali 1 sopir) (13)

9. Over Head

Damri $=10 \%$ dari sub total BOK keseluruhan

(14)

Menurut Dirjen Perhubungan Darat (2002) [6], tarif adalah besarnya biaya yang dikenakan kepada setiap penumpang kendaraan angkutan penumpang umum yang dinyatakan dalam bentuk rupiah. Perhitungan tarif angkutan umum merupakan hasil perkalian antar tarif pokok dan jarak (kilometer) rata-rata satu perjalanan (tarif BEP) dan ditambah 10\% untuk jasa keuntungan perusahaan, persamaan yang digunakan adalah sebagai berikut :

- Tarif $=($ tarif pokok $\mathrm{x}$ jarak rata-rata $)+10 \%(15)$

- Tarif BEP = tarif pokok x jarak rata-rata

- $\quad$ Tarif Pokok = "BOK" /("Faktor pengisian x kapasitas Kendaraan")

\section{HASIL DAN PEMBAHASAN}

\section{Perhitungan Biaya Operasional Kendaraan}

Berikut data karakteristik Bus Damri rute BIL Kota Mataram, (GM Perum Damri Mataram, 2020) :

- Merek Kendaraan Damri $\quad$ : Hino Dutro

- Jenis Kendaraan : Medium Bus

- Kapasitas Penumpang : 27 Orang

- Harga Kendaraan (2012) : :Rp 800.000.000

- Harga satuan Ban $\quad$ : Rp 1.830.000

- Upah Mekanik mesin perbulan min : Rp 1.050.000

- Upah Perjalanan Sopir perbulan : Rp 1.050.000

- Harga satuan BBM solar/per liter : Rp 5.150.00

- Harga satuan pelumas (oli) / l : Rp 29.700.00

- Jumlah Keseluruhan : 11 unit

- Sistem setoran : Perhari

- Tarif

: Rp 30.000

- Uang dinas jalan sebesar 7\% dari jumlah setoran perhari

Perhitungan BOK Bus Damri untuk harga masingmasing komponen secara lengkap ditampilkan di atas. Jika diambil kecepatan rata-rata berjalan (Running Speed) Bus Damri adalah V $=60 \mathrm{~km} / \mathrm{jam}$. Berikut hasil perhitungan komponen BOK Bus Damri menggunakan metode PCI :

1. Biaya Konsumsi Bahan Bakar

$\mathrm{Y}=0,06846 \times \mathrm{S} 2-8,02987 \times \mathrm{S}+340,604 \times \mathrm{Rp} 5.150$

$=\{(0,06846 \times 602)-(8,02987 \times 60)\}+340,604 \times R p$ $5.150=\operatorname{Rp} 542.129,2,-$

2. Biaya Konsumsi Oli Mesin
$\mathrm{Y}=0,00057 \times \mathrm{S} 2-0,06130 \times \mathrm{S}+3,317530 \times \mathrm{Rp} 29.700$

$=\{(0,00057 \times 602)-(0,06130 \times 60)\}+3,317530 \times \mathrm{Rp}$

$29.700=\operatorname{Rp} 50.238,441,-$

3. Biaya Pemakaian Ban

- $\mathrm{Y}=0,0012356 \times \mathrm{S}-0,0064667$

$=(0,0012356 \times 60)-0,0064667=0,067669$

- $\quad Y^{\prime}=$ Y x Jumlah Ban x Harga Ban/100o Km

$=0,067669 \times 6 \times \operatorname{Rp} 1.830 .000,-/ 1000=R p$ 743,01

4. Biaya Pemeliharaan

Biaya Pemeliharaan untuk Onderdil

$\mathrm{Y}=0,0000320 \times \mathrm{S}+0,0020891$

$=(0,0000320 \times 60)+0,0020891=0,0040091$

Y1' $=$ Y x Nilai Kendaraan/1000 Km

$=0,0040091 \times \mathrm{Rp} 800.000 .000,-/ 1000$

$=\operatorname{Rp} 3.207,280$,-

- Biaya Pemeliharaan untuk Pekerja

$\mathrm{Y}=0,02311 \times \mathrm{S}+1,97733$

$=\{(0,02311 \times 60)+1,97733\}=3,3639$

Y2' $=$ Y x Ongkos Mekanik Perhari/1000 Km

$=3,3639 \times(\operatorname{Rp} 35.000,-/ 8$ jam $/$ hari $)$

$=\operatorname{Rp} 14.717,06,-$

- Biaya Pemeliharaan Total

$\mathrm{Y}=\mathrm{Y} 1^{\prime}+\mathrm{Y} 2^{\prime}$

$=$ Rp 3.27,280,- + Rp 14.717,06,- = Rp 17.924,34,-

5. Biaya Penyusutan Kendaraan

$\mathrm{Y}=1 /((8,756 \times \mathrm{S})+350) \times$ harga kendaraan

$=1 /((8,756 \times 60)+350) \times \mathrm{Rp} 800.000 .000,-$

$=\operatorname{Rp} 913.910,-$

6. Biaya untuk Suku Bunga

$\mathrm{Y}=120 /(2500 \mathrm{~S}) \times 0,5 \times$ harga kendaraan

$=120 /(2500 \times 60) \times 0,5 \times \mathrm{Rp} 800.000 .000,-$

$=\operatorname{Rp} 320.000,-$

7. Biaya untuk Asuransi

$\mathrm{Y}=(40,0 \times 0,5) /(2500 \mathrm{~S}) \mathrm{x}$ harga kendaraan

$=(40,0 \times 0,5) /(2500 \times 60) \times \mathrm{Rp} 800.000 .000,-$

$=\mathrm{Rp} 106.666,6,-$

8. Biaya Crew

$\mathrm{Y}=1000 / \mathrm{S} \times$ upah crew perhari (faktor pengali 1 sopir)

$=1000 / 60 \times 35000=\operatorname{Rp} 583.333,3,-$

9. Over Head

Damri $=10 \%$ dari sub total BOK keseluruhan

$=\quad 10 \quad \% \quad \mathrm{x}$

$(542.129,2+50.238,441+743,01+17.924,34+$

$913.910+320.000+106.666,6+583.333,3)$

$=10 \%$ x 2.534.944,3

$=\operatorname{Rp} 253.494,43,^{-}$ 
Total BOK dari Bus Damri :

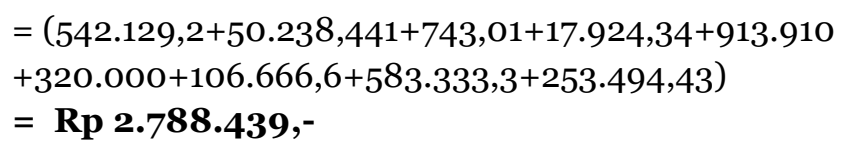

Jadi, Total Biaya Operasional Kendaraan (BOK) Bus Damri rute BIL - Kota Mataram menggunakan metode PCI adalah Rp 2.788.439,--

\section{Perhitungan Tarif Berdasarkan BOK}

- Berikut perhitungan tarif Bus Damri rute BIL Kota Mataram berdasarkan Biaya Operasional Kendaraan pada waktu Bus Damri beroperasi pagi hari :

Tarif pokok = BOK/("Faktor Pengisian x kap. kend") $=(2.788 .439 / 1000) /((7 /(27) \times 100 \%) \times 27)$ $=\operatorname{Rp} 398,3484$

Tarif BEP $=$ Tarif Pokok $\mathrm{x}$ jarak rata-rata $=398,3484 \times 33,68$ $=\operatorname{Rp} 13 \cdot 416,38$

$$
\begin{aligned}
\text { Tarif } & =\text { Tarif BEP }+10 \% \text { Tarif BEP } \\
& =13 \cdot 416,38+1.341,638 \\
& =\operatorname{Rp} 14 \cdot 758,01,-
\end{aligned}
$$

Jadi, tarif Bus Damri rute Bandara - Kota Mataram berdasarkan Biaya Operasional Kendaraan pada waktu Bus Damri beroperasi pagi hari adalah Rp 14.758,01,-

- Berikut perhitungan tarif Bus Damri rute BIL Kota Mataram berdasarkan Biaya Operasional Kendaraan pada waktu Bus Damri beroperasi siang hari :

Tarif pokok = BOK/("Faktor Pengisian x kap. kend") $=(2.788 .439 / 1000) /((8 /(27) \times 100 \%) \times 27)$ $=\operatorname{Rp} 348,5549$

Tarif BEP = Tarif Pokok $\mathrm{x}$ jarak rata-rata $=348,5549 \times 33,68$ $=\operatorname{Rp} 11.739,33$

Tarif $=$ Tarif BEP $+10 \%$ Tarif BEP $=1.739,33+1.173,933$ $=\operatorname{Rp} 12.913,26,-$

Jadi, tarif Bus Damri rute Bandara - Kota Mataram berdasarkan Biaya Operasional Kendaraan pada waktu Bus Damri beroperasi siang hari adalah Rp 12.913,26,-

- Berikut perhitungan tarif Bus Damri rute BIL - Kota Mataram berdasarkan Biaya Operasional Kendaraan pada waktu Bus Damri beroperasi sore hari :

Tarif pokok = BOK/("Faktor Pengisian $\mathrm{x}$ kap. kend") $=(2.788 .439 / 1000) /((3 /(27) \times 100 \%) \times 27)$ $=\operatorname{Rp} 929,4797$

Tarif BEP = Tarif Pokok $\mathrm{x}$ jarak rata-rata $=929,4797 \times 33,68$
$=\operatorname{Rp} 31.304,88$

$$
\begin{aligned}
\text { Tarif } & =\text { Tarif BEP }+10 \% \text { Tarif BEP } \\
& =31.304,88+3.130,488 \\
& =\operatorname{Rp} 34.435,36,-
\end{aligned}
$$

Jadi, tarif Bus Damri rute Bandara - Kota Mataram berdasarkan Biaya Operasional Kendaraan pada waktu Bus Damri beroperasi sore hari adalah Rp 34.435,36,-

\section{SIMPULAN DAN SARAN}

Berdasarkan hasil analisa dan pembahasan diatas maka diketahui Biaya Operasional Kendaraan (BOK) Bus Damri rute Bandara Internasional Lombok (BIL) Kota Mataram sebesar Rp 2.788.439 dengan kecepatan berjalan (Running Speed) dari Bus Damri yaitu 60 $\mathrm{km} / \mathrm{jam}$.

Sedangkan dari hasil analisa tarif yang dibagi menjadi 3 waktu yaitu pagi hari, siang hari dan sore hari, diketahui tarif rata-rata pada waktu pagi hari sebesar Rp 15.015, siang hari sebesar Rp 13.223 dan sore hari sebesar Rp 42.262.

Kemudian untuk biaya rata-rata tarif diketahui sebesar Rp 23.499,89 per hari, dengan tarif sebenarnya sebesar Rp 30.000. Berdasarkan perhitungan tarif bus damri untuk rute Bandara Internasional Lombok - Kota Mataram didapatkan harga tarif sebenarnya mendekati posisi penumpang paling sedikit. Hal ini menunjukan hasil analisis tarif dengan tarif sebenarnya masih sesuai.

\section{DAFTAR RUJUKAN}

[1] B. P. S. Kota Mataram, "Proyeksi Jumlah Penduduk Kota Mataram Tahun 2011-2020." Mataram, 2020.

[2] F. S. Mawu, T. K. Sendow, and J. E. Waani, "Tinjauan Tarif Angkutan Umum Dalam Kota Akibat Perubahan Harga Bbm (Studi Kasus : Trayek Pusat Kota - Malalayang)," J. Sipil Statik, vol. 4, no. 3, pp. 165-173, 2016.

[3] R. Barros, A. Winaya, and M. Firdausi, "Evaluasi Tarif Berdasarkan Biaya Operasional Kendaraan (BOK) di Terminal Purabaya (Bungurasih) untuk Bus Damri P8,” vol. 1, no. 1, pp. 7-11, 2020.

[4] T. K. Sukwanti, "Kajian Dampak Perubahan Biaya Operasional Kendaraan ( Bok ) Akibat Pengalihan Arus Lalu Lintas Dari Ruas Jalan Cadas Pangeran Ke Jalur Alternatif,” vol. 23, no. 1, pp. 1-18, 2012.

[5] A. T. Lestari, "Hubungan antara Kerusakan Jalan dan Biaya Operasional Kendaraan Pada Jalan Kolektor Perkotaan Jember,” Rekayasa sipil dan Lingkung., vol. 2, no. 1, pp. 57-66, 2018.

[6] Direktur Jenderal Perhubungan Darat, Pedoman Teknis Penyelenggaraan Angkutan Penumpang Umum di Wilayah Perkotaan dalam Trayek Tetap dan Teratur, no.SK.687/AJ.206/DRJD/2002. Indonesia, 2002, pp. 2-69. 